\title{
Amputation, psychological consequences, and quality of life among Romanian
} patients

\author{
Alin Cristinel Cotigă***, Mirela Zivari*, Adrian Cursaru********, Cătălin Aliuș****, \\ Claudiu Ivan****** \\ *Department of Psychology, University Emergency Hospital, Bucharest, Romania \\ **Department of Psychology, University of Bucharest, Bucharest, Romania \\ $* * *$ Department of Orthopaedics and Traumatology, University Emergency Hospital, Bucharest, Romania \\ $* * * *$ Department of General Surgery, University Emergency Hospital, Bucharest, Romania \\ $* * * * *$ "Carol Davila" University of Medicine and Pharmacy, Bucharest, Romania \\ $* * * * * *$ Research Centre for Education and Life Chances, Bucharest, Romania
}

Correspondence to: Alin Cristinel Cotigă, PhD, Department of Psychology, Faculty of Psychology and Educational Sciences, University of Bucharest, 9o Panduri Street, District 5, Code 050663, Bucharest, Romania,

E-mail: alincotiga@gmail.com

\begin{abstract}
Amputation of the limb is a major psychological health issue that was not fully studied. Patients and their families struggle with symptoms of depression, posttraumatic stress disorder, anxiety, phantom limb phenomena, etc. There is also a tremendous impact on the person's quality of life.

Aim: This study aimed to assess the psychological symptoms of depression, anxiety, and the quality of life among persons suffering from amputation of the limb.

Methods: 31 respondents agreed to participate in the study. They were recruited from the Department of Orthopaedics and Traumatology, University Emergency Hospital, Bucharest, Romania. The medical conditions and the socio-demographic data (i.e., gender, marital status, income, etc.) along with the assessment of the psychological conditions and quality of life were contributions to the statistical analysis of the study.

Results: This study showed that levels of depression are moderate to severe for a significant percent of the population (i.e., a "moderate to severe" or "severe" level of depression was presented by $29 \%$ of the patients according to the PHQ-9 test, and $16.1 \%$ of the patients according to Beck's Depression Inventory). Moreover, the levels of anxiety were relatively higher than those of the general population (i.e., severe anxiety was confirmed by the GAD-7 test in the case of $38.7 \%$ of the patients) and for most of them the quality of life was impaired.

Discussion: Amputation occurs mainly in adults/ elderly aged over 50 years, married, living in urban areas, with different levels of depression and anxiety. At least half of them had a self-perceived health condition that was deteriorated, their physical and role functioning being primarily affected.

Conclusion: There is a need for psychological support of the patients suffering from limb amputation as most of the studies showed high prevalence of depression and anxiety. Socio-demographic factors also represent important elements in defining the quality of life of those patients.

Keywords: amputation, anxiety, depression, quality of life, rehabilitation
\end{abstract}




\section{Introduction}

Amputation of the limb represents a major event in a person's life with consequences that have not been fully studied. Physical consequences are mainly related to the inability to perform different life tasks, which were part of the person's life before. This creates a tremendous stress [1] that interferes with the person's life. There is a series of events and medical conditions that result in the amputation of the limb, like diabetes, secondary infection, peripheral vascular disease, tumor and psychiatric conditions. There are different types of amputation: foot, ankle, transtibial, through knee, and transfemoral [2].

After the amputation, most of the patients express psychological problems like anxiety [35], depression [3-7], posttraumatic stress disorder and pain [8], etc., which affect their quality of life [9-11], along with their medical condition. There are patients who develop "mutilation anxiety" [1] and change their selfesteem due to changes suffered by their body image [12]. Moreover, 50\%-80\% of the amputee patients experience a phantom limb pain, while others develop residual limb pain, back pain, contralateral join pain [8].

\section{Study design}

A cross-sectional survey involving the Department of Orthopaedics and Traumatology of the University Emergency Hospital, Bucharest, Romania, was made. A cohort of 31 patients agreed to participate in this study. This study obtained the institutional review board approval from the Ethics Committee of the University Emergency Hospital, Bucharest.

\section{Study setting and population}

A set of self-report questionnaires designed to measure depression, anxiety, and the quality of life, was distributed.
Questionnaires were administered to 31 respondents under the direct supervision of a clinical psychologist, with the permission of their attending physician. Special attention was paid to the informed consent of each respondent in the study.

\section{Instruments}

EORTC QLQ-C30 (3 $3^{\text {rd }}$ version) is a selfreport inventory, which consists of 30 items measuring the quality of life of clinical patients [13]. Items are scored on a four-point Likert scale, except for the $29^{\text {th }}$ and the $30^{\text {th }}$ items that are scored on a seven-point Likert scale. An example of using EORTC QLQ-C30 was illustrated by King [14].

PHQ-9 (Patient Health Questionnaire-9) is a screening instrument, widely accepted for assessing the degree of depression severity in clinical patients [15]. The instrument has 9 items that are scored on a four-point Likert scale.

GAD-7 (General Anxiety Disorder-7) is also a screening instrument, widely accepted for the measurement of the severity of anxiety in clinical patients [16]. The instrument has 7 items that are scored on a four-point Likert scale.

Beck's Depression Inventory-Second Edition (BDI-II) - Romanian version is a selfreport inventory that consists of 21 items designed to measure depression symptoms in adolescents and adults and represents a revised version of Beck's Depression Inventory [17]. Most of the items are scored on a fourpoint Likert scale, except for the $16^{\text {th }}$ and the $18^{\text {th }}$ items that are scored on a seven-point Likert scale.

\section{Results}

The profile of the study consisted of the 31 respondents who underwent an amputation surgical procedure through a set of relevant 
socio-demographic data (see Table 1). The variable "age" was coded into six predefined categories, 25 patients (80.6\%) being over 50 and $64.5 \%$ being males. Most patients were married $(58.1 \%)$, one in four patients resided in rural area (25.8\%). $29 \%$ of the patients had at most completed primary or secondary school, $61.3 \%$ of the patients had completed vocational school or high school, and only 9.7\% had higher education.

Approximately one in three patients (35.5\%) considered that their financial situation was below average, $54.8 \%$ evaluated their financial condition as average, and 9.7\% considered that their financial situation was above average. Most patients were retired $(61.3 \%)$ and one of them (3.2\%) was unemployed; the remaining members of the target group worked in different fields of activity. One in two patients was a smoker (51.6\%), 19.4\% were former smokers and 29\% were non-smokers. Most patients (54.8\%) indicated that their relatives did not "ever" suggest to them that they drank too much, for
$29 \%$ it was sometimes suggested that they drank "occasionally" and for $16.1 \%$ of them, their relatives often suggested them that they drank "too much".

One in two patients underwent a surgical amputation in the past six months, $12.9 \%$ within 6-12 months, $19.4 \%$ between one and two years and $16.1 \%$ over three years, starting from the moment the questionnaire was applied. Of all the patients, 71\% underwent psychological counseling treatment. One in three patients (32.3\%) declared they accommodated "easily" or "very easily" to the new body image, and one in three mentioned they accommodated "quite hard" or "hard" to the new image, while $35.5 \%$ declared they have found it very difficult to adapt to the new body image.

The medical diagnosis for the 31 patients varied quite widely, most being diagnosed with "Lower limb amputation" (i.e., nine cases), "Gangrene" (i.e., four cases) and "Lower limb obliterative arteriopathy" (i.e., four cases).

Table 1. Respondents who underwent an amputation surgical procedure through a set of relevant socio-demographic data

\begin{tabular}{|c|c|c|c|c|c|}
\hline Age & Frequency & Percent & $\begin{array}{l}\text { Have your relatives ever } \\
\text { suggested that you drank too } \\
\text { much? }\end{array}$ & Frequency & Percent \\
\hline $18-29$ & 2 & 6.5 & often & 5 & 16.1 \\
\hline $30-39$ & 1 & 3.2 & sometimes & 9 & 29 \\
\hline $40-49$ & 3 & $9 \cdot 7$ & never & 17 & 54.8 \\
\hline $50-59$ & 5 & 16.1 & Total & 31 & 100 \\
\hline $60-6 g$ & 13 & 41.9 & $\begin{array}{l}\text { How long ago was the amputation } \\
\text { performed? }\end{array}$ & Frequency & Percent \\
\hline $70-79$ & 7 & 22.6 & Under six months & 16 & 51.6 \\
\hline Total & 31 & 100 & Between 6 and 12 months & 4 & 12.9 \\
\hline Gender & Frequency & Percent & Between 1 and 2 years & 6 & $19 \cdot 4$ \\
\hline Male & 20 & 64.5 & Over three years & 5 & 16.1 \\
\hline Female & 11 & $35 \cdot 5$ & Total & 31 & 100 \\
\hline Total & 31 & 100 & $\begin{array}{l}\text { Therapy followed by } \\
\text { psychological counseling }\end{array}$ & Frequency & Percent \\
\hline Marital status & Frequency & Percent & yes & 22 & 71 \\
\hline Single & 4 & 12.9 & no & 9 & 29 \\
\hline Married & 18 & 58.1 & Total & 31 & 100 \\
\hline
\end{tabular}




\begin{tabular}{|c|c|c|c|c|c|}
\hline Divorced & 1 & 3.2 & $\begin{array}{l}\text { Number of psychological } \\
\text { counseling sessions before } \\
\text { amputation }\end{array}$ & Frequency & Percent \\
\hline Widow & 8 & 25.8 & 0 & 25 & 80.6 \\
\hline Total & 31 & 100 & 1 & 5 & 16.1 \\
\hline Residence & Frequency & Percent & 3 & 1 & 3.2 \\
\hline $\begin{array}{l}\text { Urban - } \\
\text { municipality/large } \\
\text { city }\end{array}$ & 18 & 58.1 & Total & 31 & 100 \\
\hline $\begin{array}{l}\text { Urban-small cityl } \\
\text { town }\end{array}$ & 5 & 16.1 & $\begin{array}{l}\text { Number of psychological } \\
\text { counseling sessions after } \\
\text { amputation }\end{array}$ & Frequency & Percent \\
\hline Rural & 8 & 25.8 & 0 & 11 & $35 \cdot 5$ \\
\hline Total & 31 & 100 & 1 & 11 & $35 \cdot 5$ \\
\hline Education level & Frequency & Percent & 2 & 5 & 16.1 \\
\hline $\begin{array}{l}\text { Primary education } \\
\text { Lower-secondary } \\
\text { education } \\
\text { (qymnasium) }\end{array}$ & 4 & 12.9 & Total & 4 & 12.9 \\
\hline Vocational school & 10 & 32.3 & $\begin{array}{l}\text { Accommodation with the new } \\
\text { body image }\end{array}$ & Frequency & Percent \\
\hline $\begin{array}{l}\text { High-school/post- } \\
\text { secondary education }\end{array}$ & 9 & 29 & Very easy & 3 & 9.7 \\
\hline Higher education & 3 & 9.7 & Easy & 7 & 22.6 \\
\hline Total & 31 & 100 & Quite difficult & 4 & 12.9 \\
\hline Financial condition & Frequency & Percent & Difficult & 6 & 19.4 \\
\hline Far below average & 1 & 3.2 & Very difficult & 11 & $35 \cdot 5$ \\
\hline Below average & 10 & 32.3 & Total & 31 & 100 \\
\hline Average & 17 & 54.8 & Diagnosis & Frequency & Percent \\
\hline Above average & 3 & 9.7 & Thigh amputation & 3 & 9.7 \\
\hline Total & 31 & 100 & Gangrene & 4 & 12.9 \\
\hline $\begin{array}{l}\text { Profession/field of } \\
\text { activity }\end{array}$ & Frequency & Percent & Lower limb amputation & 9 & 29 \\
\hline $\begin{array}{l}\text { Industry } \\
\text { Economy }\end{array}$ & 7 & 22.6 & $\begin{array}{l}\text { Obliterating arteriopathy of the } \\
\text { lower limb } \\
\text { Atherosclerotic coronary heart }\end{array}$ & 4 & 12.9 \\
\hline & 1 & 3.2 & disease & 3 & 9.7 \\
\hline Trade & 2 & 6.5 & Necrotizing fasciitis & 1 & 3.2 \\
\hline Free lancer & 1 & 3.2 & Thrombosis & 1 & 3.2 \\
\hline Retired & 19 & 61.3 & Ischemia & 1 & 3.2 \\
\hline Unemployed & 1 & 3.2 & Multiple injury & 2 & 6.5 \\
\hline Total & 31 & 100 & Lobectomy & 1 & 3.2 \\
\hline Smoker & Frequency & Percent & Mastectomy & 1 & 3.2 \\
\hline Yes & 16 & 51.6 & Mandible section amputation & 1 & 3.2 \\
\hline No & 9 & 29 & Total & 31 & 100 \\
\hline Former smoker & 6 & 19.4 & & & \\
\hline Total & 31 & 100 & & & \\
\hline
\end{tabular}


The tests applied to assess the level of depression or anxiety of patients showed a relatively uniform distribution thereof (see Table 2). The alpha coefficient for PHQ-9 was 0.892 and for GAD-7 was 0.929, suggesting that the items had a relatively high internal consistency. According to the PHO-9 test,
$29 \%$ of the patients presented a "moderate to severe" or "severe" level of depression; Beck's Depression Inventory-Second Edition (BDI-II) test instead showed a share of $16.1 \%$ of the patients with severe depression. Severe anxiety was confirmed by the GAD-7 test in the case of $38.7 \%$ of the patients.

Table 2. Tests applied to assess the level of depression or anxiety

\begin{tabular}{|c|c|c|}
\hline PHO-9 (Patient Health Questionnaire-9) & Frequency & Percent \\
\hline Minimal or none Monitor depression; may not require treatment & 7 & 22.6 \\
\hline Mild depression & 7 & 22.6 \\
\hline Moderate depression & 8 & 25.8 \\
\hline Moderate severe depression & 4 & 12.9 \\
\hline Severe depression & 5 & 16.1 \\
\hline Total & 31 & 100 \\
\hline GAD-7 (General Anxiety Disorder-7) & Frequency & Percent \\
\hline No anxiety disorder & 7 & 22.6 \\
\hline Mild anxiety & 8 & 25.8 \\
\hline Moderate anxiety & 4 & 12.9 \\
\hline Severe anxiety & 12 & 38.7 \\
\hline Total & 31 & 100 \\
\hline Beck's Depression Inventory-Second Edition (BDI-II) & Frequency & Percent \\
\hline Minimal depression & 11 & $35 \cdot 5$ \\
\hline Mild depression & 6 & 19.4 \\
\hline Moderate depression & 9 & 29 \\
\hline Severe depression & 5 & 16.1 \\
\hline Total & 31 & 100 \\
\hline
\end{tabular}

Patients were also evaluated in terms of quality of their life using the EORTC QLQ-C 30 $3^{\text {rd }}$ version) self-report inventory. This patients' assessment tool contained three analytical dimensions: A) global health status, B) functional scales and C) symptom scales/ items. In interpreting the results of this instrument, one should take into account that, as mentioned in the manual of the EORTC QLQ-C3O (3 ${ }^{\text {rd }}$ version), "a high score for a functional scale represents a high/ healthy level of functioning, and a high score for the global health status/ OOL represents a high QOL, but a high score for a symptom scale/ item represents a high level of symptomatology/ problems" [18]. The alpha coefficient for EORTC QLQ-C30 ( $3^{\text {rd }}$ version) was 0.876 , suggesting that the items had a relatively high internal consistency.

A. Global health status - high score for the global health status/ QOL represents a high QOL

The data showed that $63.1 \%$ of the patients (i.e., 19 out of 31), self-assessed their health at a level lower than 50 on a scale of 0 to 100; on the other hand, the highest level of health was 66.7 on the same scale from o to 100 (see Table 3). 
Table 3. GHSscore

\begin{tabular}{llcccc}
\hline \multirow{4}{*}{ Valid } & Frequency & Percent & Valid Percent & Cumulative Percent \\
& .00 & 1 & 3.2 & 3.2 & 3.2 \\
\hline 8.33 & 2 & 6.5 & 6.5 & 9.7 \\
\hline 16.67 & 6 & 19.4 & 19.4 & 29.0 \\
\hline 25.00 & 3 & 9.7 & 9.7 & 38.7 \\
33.33 & 5 & 16.1 & 16.1 & 54.8 \\
41.67 & 2 & 6.5 & 6.5 & 61.3 \\
\hline 50.00 & 7 & 22.6 & 22.6 & 83.9 \\
58.33 & 3 & 9.7 & 9.7 & 93.5 \\
66.67 & 2 & 6.5 & 6.5 & 100.0 \\
\hline
\end{tabular}

B. Functional scales - a high score for a functional scale represents a high/healthy level of functioning

Table 4. Physical functioning - PFscore

\begin{tabular}{|c|c|c|c|c|c|}
\hline \multirow{16}{*}{ Valid } & & Frequency & Percent & Valid Percent & Cumulative Percent \\
\hline & .00 & 8 & 25.8 & 25.8 & 25.8 \\
\hline & 6.67 & 1 & 3.2 & 3.2 & 29.0 \\
\hline & 13.33 & 3 & 9.7 & 9.7 & 38.7 \\
\hline & 20.00 & 1 & 3.2 & 3.2 & 41.9 \\
\hline & 26.67 & 2 & 6.5 & 6.5 & 48.4 \\
\hline & $33 \cdot 33$ & 1 & 3.2 & 3.2 & 51.6 \\
\hline & 40.00 & 3 & 9.7 & 9.7 & 61.3 \\
\hline & 46.67 & 3 & 9.7 & 9.7 & 71.0 \\
\hline & $53 \cdot 33$ & 1 & 3.2 & 3.2 & 74.2 \\
\hline & 60.00 & 2 & 6.5 & 6.5 & 80.6 \\
\hline & 66.67 & 2 & 6.5 & 6.5 & 87.1 \\
\hline & $73 \cdot 33$ & 1 & 3.2 & 3.2 & 90.3 \\
\hline & 80.00 & 2 & 6.5 & 6.5 & 96.8 \\
\hline & 86.67 & 1 & 3.2 & 3.2 & 100.0 \\
\hline & Total & 31 & 100.0 & 100.0 & \\
\hline
\end{tabular}

The following table shows the extent to which health condition had limited professional activities. $77.4 \%$ of the patients limited their role functioning (see Table 5).

Table 5. Role functioning - RFscore

\begin{tabular}{llrrrr}
\hline \multirow{2}{*}{ Valid } & Frequency & & Percent & Valid Percent & \multicolumn{2}{c}{ Cumulative Percent } \\
& 17 & 54,8 & 54,8 & 54,8 \\
& 16,67 & 2 & 6,5 & 6,5 & 61,3 \\
33,33 & 5 & 16,1 & 16,1 & 77,4 \\
50,00 & 2 & 6,5 & 6,5 & 83,9 \\
66,67 & 4 & 12,9 & 12,9 & 96,8 \\
100,00 & 1 & 3,2 & 3,2 & 100,0 \\
\hline Total & 31 & 100,0 & 100,0 & \\
\hline
\end{tabular}

Emotional functioning appeared to have been less affected compared to physical or role functioning, with $54.8 \%$ of the patients
In terms of physical functioning, $71 \%$ of the patients were below the level 50 on a scale of 0 to 100, where o showed a very low physical functionality (see Table 4).

were below the threshold 50 on a scale from 0 to 100, which means that their health severely

below the level 50 on a scale of o to 100 (see Table 6). 
Table 6. Emotional functioning - EFscore

\begin{tabular}{|c|c|c|c|c|c|}
\hline \multirow{13}{*}{ Valid } & & Frequency & Percent & Valid Percent & Cumulative Percent \\
\hline & .00 & 1 & 3.2 & 3.2 & 3.2 \\
\hline & 8.33 & 4 & 12.9 & 12.9 & 16.1 \\
\hline & 25.00 & 3 & 9.7 & 9.7 & 25.8 \\
\hline & $33 \cdot 33$ & 6 & $19 \cdot 4$ & 19.4 & 45.2 \\
\hline & 41.67 & 3 & $9 \cdot 7$ & 9.7 & 54.8 \\
\hline & 50.00 & 4 & 12.9 & 12.9 & 67.7 \\
\hline & 66.67 & 4 & 12.9 & 12.9 & 80.6 \\
\hline & 75.00 & 1 & 3.2 & 3.2 & 83.9 \\
\hline & 83.33 & 1 & 3.2 & 3.2 & 87.1 \\
\hline & 91.67 & 1 & 3.2 & 3.2 & 90.3 \\
\hline & 100.00 & 3 & $9 \cdot 7$ & 9.7 & 100.0 \\
\hline & Total & 31 & 100.0 & 100.0 & \\
\hline
\end{tabular}

Cognitive functioning was affected to an below the level 50 on the scale from o to 100, even lesser extent, $41 \%$ of the patients being where o represented the minimum level of ranked according to the answers provided, cognitive functioning (see Table 7).

Table 7. Cognitive functioning - CFscore

\begin{tabular}{|c|c|c|c|c|c|}
\hline \multirow{7}{*}{ Valid } & & Frequency & Percent & Valid Percent & Cumulative Percent \\
\hline & 33.33 & 6 & $19 \cdot 4$ & 19.4 & $19 \cdot 4$ \\
\hline & 50.00 & 7 & 22.6 & 22.6 & 41.9 \\
\hline & 66.67 & 4 & 12.9 & 12.9 & 54.8 \\
\hline & 83.33 & 5 & 16.1 & 16.1 & 71.0 \\
\hline & 100.00 & 9 & 29.0 & 29.0 & 100.0 \\
\hline & Total & 31 & 100.0 & 100.0 & \\
\hline
\end{tabular}

Family or social activities appeared to have of o to 100, while for five patients (i.e., 16.1\%) been significantly affected, $41.9 \%$ of the social functioning was at a maximum level 100 patients being ranked below level 50 on a scale on the same scale (see Table 8 ).

Table 8. Social functioning - SFscore

\begin{tabular}{|c|c|c|c|c|c|}
\hline \multirow{9}{*}{ Valid } & & Frequency & Percent & Valid Percent & Cumulative Percent \\
\hline & .00 & 5 & 16.1 & 16.1 & 16.1 \\
\hline & 16.67 & 2 & 6.5 & 6.5 & 22.6 \\
\hline & 33.33 & 6 & $19 \cdot 4$ & 19.4 & 41.9 \\
\hline & 50.00 & 1 & 3.2 & 3.2 & 45.2 \\
\hline & 66.67 & 6 & 19.4 & 19.4 & 64.5 \\
\hline & 83.33 & 6 & 19.4 & $19 \cdot 4$ & 83.9 \\
\hline & 100.00 & 5 & 16.1 & 16.1 & 100.0 \\
\hline & Total & 31 & 100.0 & 100.0 & \\
\hline
\end{tabular}

C. Symptom scales/ items - a high score for a symptom scale/ item represents a high level of symptomatology/ problems

In the case of the symptom scale, a higher score represented a negative situation and problems associated with the amputation condition. Significant fatigue symptoms level, (i.e., over $50 \%$ of the cases) were reported in $58.1 \%$ of the patients (see Table 9). 
Romanian Journal of Orthopaedic Surgery and Traumatology 2020; 3(1): 29-40

Table g. Fatigue - FSscore

\begin{tabular}{|c|c|c|c|c|c|}
\hline \multirow{12}{*}{ Valid } & & Frequency & Percent & Valid Percent & Cumulative Percent \\
\hline & .00 & 1 & 3.2 & 3.2 & 3.2 \\
\hline & 11.11 & 2 & 6.5 & 6.5 & 9.7 \\
\hline & 22.22 & 1 & 3.2 & 3.2 & 12.9 \\
\hline & 33.33 & 4 & 12.9 & 12.9 & 25.8 \\
\hline & 44.44 & 5 & 16.1 & 16.1 & 41.9 \\
\hline & $55 \cdot 56$ & 3 & 9.7 & 9.7 & 51.6 \\
\hline & 66.67 & 3 & 9.7 & 9.7 & 61.3 \\
\hline & 77.78 & 9 & 29.0 & 29.0 & 90.3 \\
\hline & 88.89 & 1 & 3.2 & 3.2 & 93.5 \\
\hline & 100.00 & 2 & 6.5 & 6.5 & 100.0 \\
\hline & Total & 31 & 100.0 & 100.0 & \\
\hline
\end{tabular}

Nausea and vomiting had a significant ratio, over 50 on the scale from o to 100 , where 100 meant a serious condition in the case of only two patients (i.e., 6.4\%), which was

normal given that the amputation did not have a direct medical impact on these conditions (see Table 10).

Table 10. Nausea and vomiting - NVSscore

\begin{tabular}{llrrrr}
\hline \multirow{3}{*}{ Valid } & \multicolumn{1}{c}{ Frequency } & & Percent & Valid Percent & Cumulative Percent \\
& \multicolumn{1}{c}{ 16.67 } & 22 & 71.0 & 71.0 & 71.0 \\
& 33.33 & 5 & 16.1 & 16.1 & 87.1 \\
& 50.00 & 2 & 6.5 & 6.5 & 93.5 \\
& 66.67 & 1 & 3.2 & 3.2 & 96.8 \\
& Total & 1 & 3.2 & 3.2 & 100.0 \\
\hline
\end{tabular}

By contrast, pain was present for 22 of the to exactly control the period and duration of 31 patients $(77.4 \%)$. However, we were unable the pain (see Table 11).

Table 11. Pain - PSscore

\begin{tabular}{|c|c|c|c|c|c|}
\hline & & Frequency & Percent & Valid Percent & Cumulative Percent \\
\hline \multirow[t]{8}{*}{ Valid } & .00 & 1 & 3.2 & 3.2 & 3.2 \\
\hline & 16.67 & 2 & 6.5 & 6.5 & 9.7 \\
\hline & 33.33 & 4 & 12.9 & 12.9 & 22.6 \\
\hline & 50.00 & 8 & 25.8 & 25.8 & 48.4 \\
\hline & 66.67 & 5 & 16.1 & 16.1 & $64 \cdot 5$ \\
\hline & 83.33 & 6 & 19.4 & $19 \cdot 4$ & 83.9 \\
\hline & 100.00 & 5 & 16.1 & 16.1 & 100.0 \\
\hline & Total & 31 & 100.0 & 100.0 & \\
\hline
\end{tabular}

Only $25.9 \%$ of the patients reported of o to 100 , the remaining ones manifested a dyspnoea above the threshold of 50 on a scale low level of dyspnoea (see Table 12).

Table 12. Dyspnoea - DSscore

\begin{tabular}{|c|c|c|c|c|c|}
\hline \multirow{6}{*}{ Valid } & & Frequency & Percent & Valid Percent & Cumulative Percent \\
\hline & .00 & 14 & 45.2 & 45.2 & 45.2 \\
\hline & 33.33 & 9 & 29.0 & 29.0 & 74.2 \\
\hline & 66.67 & 6 & 19.4 & $19 \cdot 4$ & $93 \cdot 5$ \\
\hline & 100.00 & 2 & 6.5 & 6.5 & 100.0 \\
\hline & Total & 31 & 100.0 & 100.0 & \\
\hline
\end{tabular}


Insomnia was a significant problem (above of the patients (i.e., 21 of the 31 patients who a level of 50 on a scale from o to 100) in 67.8\% were part of our survey sample) (see Table 13).

Table 13. Insomnia - ISscore

\begin{tabular}{|c|c|c|c|c|c|}
\hline \multirow{6}{*}{ Valid } & & Frequency & Percent & Valid Percent & Cumulative Percent \\
\hline & .00 & 6 & 19.4 & 19.4 & 19.4 \\
\hline & 33.33 & 4 & 12.9 & 12.9 & 32.3 \\
\hline & 66.67 & 11 & $35 \cdot 5$ & $35 \cdot 5$ & 67.7 \\
\hline & 100.00 & 10 & 32.3 & 32.3 & 100.0 \\
\hline & Total & 31 & 100.0 & 100.0 & \\
\hline
\end{tabular}

Loss of the appetite was a significant symptom (on a level above 50 on a scale from o to 100) for $41.9 \%$ of the patients (see Table 14 ).

Table 14. Appetite loss - ALSscore

\begin{tabular}{|c|c|c|c|c|c|}
\hline \multirow{6}{*}{ Valid } & & Frequency & Percent & Valid Percent & Cumulative Percent \\
\hline & .00 & 5 & 16.1 & 16.1 & 16.1 \\
\hline & 33.33 & 13 & 41.9 & 41.9 & 58.1 \\
\hline & 66.67 & 9 & 29.0 & 29.0 & 87.1 \\
\hline & 100.00 & 4 & 12.9 & 12.9 & 100.0 \\
\hline & Total & 31 & 100.0 & 100.0 & \\
\hline
\end{tabular}

Only $13 \%$ of the patients reported a significant level of constipation-related symptoms and only $3.2 \%$ experienced significant diarrhea symptoms (see Table 15, 16).

Table 15. Constipation - CSscore

\begin{tabular}{|c|c|c|c|c|c|}
\hline \multirow{6}{*}{ Valid } & & & Percent & Valid Percent & Cumulative Percent \\
\hline & .00 & 13 & 41.9 & 41.9 & 41.9 \\
\hline & $33 \cdot 33$ & 14 & 45.2 & 45.2 & 87.1 \\
\hline & 66.67 & 2 & 6.5 & 6.5 & 93.5 \\
\hline & 100.00 & 2 & 6.5 & 6.5 & 100.0 \\
\hline & Total & 31 & 100.0 & 100.0 & \\
\hline
\end{tabular}

Table 16. Diarrhea-DiarScore

$\begin{array}{llrrrr} & & \text { Frequency } & \text { Percent } & \text { Valid Percent } & \text { Cumulative Percent } \\ \text { Valid } & 100 & 28 & 90,3 & 90,3 & 90,3 \\ & 33,33 & 2 & 6,5 & 6,5 & 96,8 \\ & 66,67 & 1 & 3,2 & 3,2 & 100,0 \\ & \text { Total } & 31 & 100,0 & 100,0 & \end{array}$

Financial difficulties are one aspect that seemed to have marked the majority of the patients who underwent amputation: $58.1 \%$ of the patients declared that they faced financial difficulties at a level above 50 on a scale from 0 to 100 - where 100 was a maximum level of financial difficulties (see Table 17).

Table 17. Financial difficulties - FinancialDScore

\begin{tabular}{|c|c|c|c|c|c|}
\hline \multirow{6}{*}{ Valid } & & Frequency & Percent & Valid Percent & Cumulative Percent \\
\hline & .00 & 5 & 16.1 & 16.1 & 16.1 \\
\hline & $33 \cdot 33$ & 8 & 25.8 & 25.8 & 41.9 \\
\hline & 66.67 & 9 & 29.0 & 29.0 & 71.0 \\
\hline & 100.00 & 9 & 29.0 & 29.0 & 100.0 \\
\hline & Total & 31 & 100.0 & 100.0 & \\
\hline
\end{tabular}


The table below summarizes the share of patients who manifested a significant level in terms of problems, set at 50 on a scale from $o$ to 100 , for each of the issues considered by the quality of life assessment scale.

Table 18. Patients who manifested a significant level in terms of problems for each of the issues considered by the quality of life assessment scale

\begin{tabular}{|c|c|c|c|}
\hline $\begin{array}{l}\text { EORTC OLQ-C30 } \\
\left(3^{\text {rd }} \text { version) self- }\right. \\
\text { report inventory }\end{array}$ & $\begin{array}{c}\text { A. Global health status, } \\
\text { share of patients with a } \\
\text { score }<50 \text { on the scale from } \\
\text { o to } 100\end{array}$ & $\begin{array}{c}\text { B. Functional scales, } \\
\text { share of patients with a } \\
\text { score }<50 \text { on the scale } \\
\text { from o to } 100\end{array}$ & $\begin{array}{l}\text { C. Symptom scales/ items, } \\
\text { share of patients with a score } \\
>50 \text { on the scale from o to } 100\end{array}$ \\
\hline $\begin{array}{l}\text { Global health } \\
\text { status }\end{array}$ & $61.30 \%$ & & \\
\hline $\begin{array}{l}\text { Physical } \\
\text { functioning }\end{array}$ & & $71 \%$ & \\
\hline Role functioning & & $77.40 \%$ & \\
\hline $\begin{array}{l}\text { Emotional } \\
\text { functioning }\end{array}$ & & $54.80 \%$ & \\
\hline $\begin{array}{l}\text { Cognitive } \\
\text { functioning }\end{array}$ & & $41 \%$ & \\
\hline Social functioning & & $41.90 \%$ & \\
\hline Fatigue & & & $58.10 \%$ \\
\hline $\begin{array}{l}\text { Nausea and } \\
\text { vomiting }\end{array}$ & & & $6.40 \%$ \\
\hline Pain & & & $77.40 \%$ \\
\hline Dyspnoea & & & $25.90 \%$ \\
\hline Insomnia & & & $67.80 \%$ \\
\hline Appetite loss & & & $41.90 \%$ \\
\hline Constipation & & & $13 \%$ \\
\hline Diarrhea & & & $3.20 \%$ \\
\hline $\begin{array}{l}\text { Financial } \\
\text { difficulties }\end{array}$ & & & $58.10 \%$ \\
\hline
\end{tabular}

The association analysis of the applied test results and the socio-demographic characteristics showed that there were no significant correlations between them. Basically, there is no specific profile or certain characteristics of patients that indicate a high probability of association with a depressive disorder or anxiety. An explanation for this finding may reside in the small number of cases in the sample.

\section{Discussion}

There are several limitations of the study. First, there was a small cohort of participants in the study, which restricted the propensity for more complex statistics. All the participants were inpatients of the Department of Orthopaedics and Traumatology, University Emergency Hospital, Bucharest, thus, limited the comprehension of such a complex phenomenon like the quality of life. Limited statistical analysis showed that few factors correlated.

The analysis of the data collected from 31 patients who underwent amputation made it possible to draw a socio-demographic profile in an exploratory manner. Thus, it seems that 
amputation mainly occurs in adults/elderly aged over 50 years $(80.6 \%$ of the patients in our sample galled within this age category). Furthermore, patients suffering from amputations were rather males $(64.5 \%$ of the total sample), a characteristic confirmed by other studies [2], married, living in urban areas, had a primary, lower-secondary or high school education level and most of them were retied. In terms of certain behaviors associated with an unhealthy lifestyle that could have led to such health problems, the data indicated that alcoholism was not prevalent among such patients - only $16.1 \%$ indicated that their relatives suggested they drank too much. Instead, smoking seemed to be a predisposing factor that led to the amputation of a part of the body, given that one in two patients was a smoker $(51.6 \%)$ and $19.4 \%$ were former smokers.

Only one in three patients (32.3\%) declared that they adjusted "easily" or "very easily" to their body image, given that $71 \%$ of the patients benefited from psychological counseling, which indicated a high degree of coverage of related support services for this type of patients. This is obviously in relation to another study using a different instrument of evaluation [11], which seems to identify psychological support and time since amputation as factors that might influence their adjustment to body image.

The data collected also showed that there were significant shares of patients suffering from mild to severe depression (29\% on the PHQ-9 scale, $16.1 \%$ according to Beck's Depression Inventory) or severe anxiety (38.7\% on the GAD-7) as demonstrated in other studies $[3-7,9]$. This suggested the need for a more consistent psychological support for patients who have underwent amputation.

EORTC QLO-C3O ( $3^{\text {rd }}$ version) self-report inventory also showed that at least half of the patients had a self-perceived health condition that was deteriorated, their physical and role functioning being primarily affected. Patients who underwent amputation also reported a significantly high level of "fatigue", "pain", "insomnia" or "financial difficulties".

The study is a first exploratory research on this topic and it allowed the setting-up of a socio-demographic, clinical (from the perspective of depressive, anxious) and social (quality of life) profile. However, more laborious statistical analyses to highlight factors favoring the association of amputation with depression or anxiety in certain patients have to be carried out in the future as the sample of patients included in such a research has to be expanded. The estimated difference between the groups of patients that we took into consideration in our sample is highly dependent on the size of sample used. An acceptable probability that there is a statistically significant evidence of a difference between the groups requires a larger sample size than we had at our disposal. It is worth mentioning that questionnaires that evaluate depressive (except for Beck's Depression Inventory) or anxious symptoms are intended for application only in the clinical setting.

\section{Conclusions}

The need to provide additional support was also confirmed by the significant share of patients with amputation suffering from depression, anxiety, pain, insomnia or fatigue. In the future, it is important to complete the sample with data collected from new patients and to survey the issues in which these patients would need more effective management (e.g., social relationships, integration into and acceptance by the family and society, reinsertion in the labor market, getting familiar with their legal rights, etc.).

\section{Conflict of Interest statements}

Authors state no conflict of interest.

Informed Consent and Human and Animal Rights statements

Informed consent has been obtained from all individuals included in this study. 


\section{Authorization for the use of human subjects}

Ethical approval: The research related to human use complies with all the relevant national regulations, institutional policies, is in accordance with the tenets of the Helsinki Declaration, and has been approved by the authors' institutional review board or equivalent commitee.

\section{References}

1. Bhuvaneswar CG, Epstein LA, Stern TA. Reaction to Amputation: Recognition and Treatment. Prim Care Companion J Clin Psychiatry. 2007; 9:303-308. https://doi:10.4088/pcc.vogno408.

2. Pezzin LE, Dillingham TR, MacKenzie EJ. Rehabilitation and the long-term outcomes of persons with traumarelated amputations. Arch Phys Med Rehabil. 2000; 81:292-300. https://doi:10.1016/s0003-9993(00)90074-1.

3. Atherton R, Robertson N. Psychological adjustment to lower limb amputation amongst prosthesis users. Disabil Rehabil. 2006; 28:1201-1209. https://doi.org/10.1080/09638280600551674.

4. Hawamdeh ZM, Othman YS, Ibrahim, Al. Assessment of anxiety and depression after lower limb amputation in Jordanian patients. Neuropsychiatr Dis Treat. 2008; 4:627-633. https://doi:10.2147/ndt.s2541.

5. Singh R, Ripley D, Pentland B, Todd I, Hunter J, Hutton L, Philip A. Depression and anxiety symptoms after lower limb amputation: the rise and fall. Clin Rehabil. 2009; 23:281-286. https://doi:10.1177/0269215508094710.

6. Cansever A, Uzun O, Yildiz C, Ates A, Atesalp AS. Depression in men with traumatic lower part amputation: a comparison to men with surgical lower part amputation. Mil Med. 2003; 168:106-109.

7. Ghous $M$, Gul S, Siddiqi FA, Pervaiz $S$, Bano $S$. Depression; prevalence among amputees. Prof Med J. 2015; 22:263-266.

8. Perkins ZB, De'Ath HD, Sharp G, Tai NR. Factors affecting outcome after traumatic limb amputation. $\mathrm{Br} J$ Surg.2012; 99 Suppl1:75-86. https://doi:10.1002/bjs.7766.

9. Christensen J, Ipsen T, Doherty P, Langberg H. Physical and social factors determining quality of life for veterans with lower-limb amputation(s): a systematic review. Disabil Rehabil. 2016; 38:2345-2353. https://doi:10.3109/09638288.2015.1129446.

10. Grzebień A, Chabowski M, Malinowski M, Uchmanowicz I, Milan M, Janczak D. Analysis of selected factors determining quality of life in patients after lower limb amputation-a review article. Pol J Surg. 2017; 89:57-61. https://doi:10.5604/01.3001.0009.8980.

11. Zidarov D, Swaine B, Gauthier-Gagnon C. Quality of life of persons with lower-limb amputation during rehabilitation and at 3-month follow-up. Arch Phys Med
Rehabil. 2009; https://doi:10.1016/j.apmr.2008.11.003.

$90: 634-645$

12. Racy JC. Psychological aspects of amputation. In Michael JW. Atlas of Limb Prosthetics: Surgical, Prosthetic, and Rehabilitation Principle. 2nd edn., 2002, Rosemont, IL, American Academy of Orthopedic Surgeons. https://www.oandplibrary.org/alp/chap28-01.asp.

Accessed 23 January 2020.

13. Aaronson NK, Ahmedzai $S$, Bergman B, Bullinger $M$, Cull $A$, Duez, NJ, Filiberti $A$, Flechtner $H$, Fleishman $S B$, de Haes JCJM, Kaasa S, Klee M, Osoba D, Razavi D, Rofe PB, Schraub S, Sneeuw K, Sullivan M, Takeda F. The European Organization for Research and Treatment of Cancer QLQ-C30: A Quality-of-Life Instrument for Use in International Clinical Trials in Oncology. J Natl Cancer Inst.1993; https://doi.org/10.1093/jnci/85·5.365.

$85: 365-376$.

14. King MT. The interpretation of scores from the EORTC quality of life questionnaire QLQ-C30. Qual Life Res. 1996; 5:555-567. https://doi:10.1007/BFoo439229.

15. Kroenke K, Spitzer RL, Williams JBW. The PHQ-9. Validity of a brief depression severity measure. J Gen Intern Med. 2001; 16:606-613. https://doi.org/10.1046/j.1525-1497.2001.016009606.x.

16. Spitzer RL, Kroenke K, Williams JBW, Löwe B. A Brief Measure for Assessing Generalized Anxiety Disorder: The GAD-7. Arch Intern Med. 2006; 166:1092-1097. https://doi:10.1001/archinte.166.10.1092.

17. Beck AT, Ward CH, Mendelson M, Mock J, Erbaugh J. An inventory for measuring depression. Arch Gen Psychiatry. 1961; 4:561-571. https://doi.org/10.1001/archpsyc.1961.01710120031004.

18. Fayers PM, Aaronson NK, Bjordal K, Groenvold M, Curran D, Bottomley A. The EORTC OLQ-C30 Scoring Manual. 3rd edn. 2001, Brussels, European Organisation for Research and Treatment of Cancer. 